\title{
Non-pharmacological Interventions for Breathlessness in Cancer
}

\section{Introduction}

Breathlessness is a powerful experience of the mind and the body (1). It has a destructive effect on the quality of life of the sufferer and those closest to them. Breathlessness is almost ubiquitous in people living with advanced primary or secondary lung cancer and is estimated to reach a prevalence of $70-90 \%$ in advanced extra-thoracic disease (2). It can result from both systemic (e.g. activation of the inflammatory response leading to sarcopenia) and local effects (e.g. pleural effusions) of malignancy; in most people it is multifactorial. Many of the multiple contributory factors to breathlessness in advanced cancer are only partially reversible and the symptom becomes chronic (see Table 1).

The impact of breathlessness on quality of life is well-established. It is disabling, distressing to experience and to observe, frightening and associated with anxiety, anger and depression $(3,4)$. It often disturbs sleep, which in turn reduces quality of life, physical and psychological resilience.

This review focuses on the management of breathlessness in people with cancer where curative treatment for the underlying tumour is no longer possible (incurable cancer) but palliative treatments may be available. The prognosis for such patients may range from weeks to months (those with advanced incurable cancer), to years, depending on tumour characteristics, palliative treatment response and the patient's co-morbidities.

Non-pharmacological treatments for breathlessness were pioneered in palliative care and respiratory medicine. It is now essential that oncology embrace these to improve patients' quality of life. Some treatments for breathlessness improve general health (e.g. exercise) and may have an impact on disease recurrence, and are recommended for all patients with cancer. Others are specific for relieving breathlessness (e.g. facial cooling via a hand-held fan). As many involve behaviour change and the development of new habits, they are most effective if implemented early in the disease process to give time for behaviours to embed and have benefit. Many patients with incurable cancer of a longer prognosis are not seen by palliative care teams. Therefore, the active management of breathlessness needs 
to become a priority for oncologists, if health gains and quality of life are to be maximised over the course of the disease.

\section{Genesis of breathlessness}

The sensation of breathlessness is generated in the central nervous system (CNS) from afferent information from the cardio-respiratory system, higher cortical centres and the limbic system, i.e. peripheral signals are processed in the CNS to produce the feeling of being breathless (5). The severity of the sensation can vary greatly between individuals with apparently similar disease burdens and the variation in severity is at least in part related to psychological status, previous experiences and memories related to breathlessness $(3,6)$.

Signals from the amygdala and other parts of the limbic system are important in generating the feeling of being breathless through learned fear and anxiety which may be lessened by education, information and anxiety management techniques (5).

\section{Palliative care for breathlessness}

Palliative care focuses on 'management of symptoms, psychosocial support, and assistance with decision making,' putting patients' priorities at the heart of care, improving quality of life and supporting those closest to them (7). A randomised controlled trial (RCT) of early integration of palliative care versus standard oncological treatment in patients with advanced metastatic small cell lung cancer, demonstrated that those who received palliative care from diagnosis onwards had a better quality of life, fewer depressive symptoms, and a longer median survival (11.6 months v. 8.9 months, $p=0.02$ ) than those who received oncology care alone (7). Patients who received palliative care in Temel et al's trial were also less likely to be treated with aggressive oncological treatments and lived longer.

Palliative treatment for breathlessness comprises a complex intervention of non-pharmacological and, where appropriate, pharmacological interventions. As death approaches and symptoms intensify, the patient becomes physically and psychologically weaker. They may be breathless even when at rest or on the most minimal exertion, e.g. speaking, eating. At this point pharmacological management 
of breathlessness in combination with continuing appropriate non-pharmacological approaches becomes essential (8). The effort required for some nonpharmacological treatments, for example those that require significant physical or mental exertion or behaviour change, need to be reconsidered at this point as the burdens may now outweigh the benefits (9). Others, like maintaining a strong therapeutic alliance, psychological support, and the hand-held fan will be helpful throughout the course of the illness with appropriate use of drug therapy.

Even within one cancer type it is recognised that there is significant variation in prognosis. With increasingly accurate recognition of different subtypes of what would previously have been designated as one histological cancer type, more treatment pathways are opening. For some, incurable cancer is a chronic illness, needing intermittent palliative treatment, where the individual lives with the effects of cancer for a significant period of time. For others, once there is no disease-directed treatment available, death may follow quickly with a rapid escalation of distressing symptoms. It is not always possible to know which trajectory the person will have when they are first assessed.

Most adequately powered RCTs of non-pharmacological treatments in breathlessness, which include patients with any illness, have a majority of patients with chronic obstructive pulmonary disease (COPD). It is common and patients are stable for longer, in contrast to breathless people with cancer. However, there is little to suggest that the genesis or experience of breathlessness is different in different disease groups, and there may even be a 'final common pathway' at the end of life (10).

The recently defined clinical syndrome of chronic breathlessness breathlessness that persists despite treatment for the underlying condition and causes disability - applies to any underlying diagnosis (11). The general principles of management are the same for any aetiology, personalised to individuals' needs.

\section{Assessment of patient}

The first step in managing breathlessness is to detect it. A quantitative measurement and continued monitoring of breathlessness severity is still not a routine part of clinical care in patients with cancer although there are powerful clinical reasons to assess it routinely (12). 
In two pilot studies of general medical inpatients, having a breathlessness score of $\geq 4$ of 10 on a numerical rating scale (NRS) 'was strongly associated with serious adverse events during hospitalisation (odds ratio $2.85,95 \% \mathrm{Cl} 1.51-5.37, \mathrm{p}$ $=0.0009)^{\prime}(13)$.

Breathlessness severity in COPD is known to give a better indication of prognosis (figure 2, (14)) than pulmonary function tests, the standard measure of disease severity in COPD and this holds for patients with heart failure and in an older study, those terminally ill with cancer $(15,16)$.

It has long been suggested that clinicians' lack of confidence in managing breathlessness in people with cancer leads to patients learning not to mention it as it will be ignored (17). Lack of management strategies or clinical assessment tools are no longer credible reasons to avoid asking patients about breathlessness. The Dyspnoea-12 (D12) is a simple to use, validated assessment tool that encompasses the sensory (e.g. disease burden) and affective (psychological reaction to) aspects of breathlessness (18).

When breathlessness is detected, a comprehensive assessment of the patient with all possible contributory factors in mind is essential. Whilst it is important to ensure that any reversible causes of breathlessness are detected and appropriate treatment initiated (see Table 1), it is just as important to listen carefully to the individual's experience of breathlessness and understand the needs of those closest to them. There is some evidence to suggest that under-researched areas like the clinician-patient rapport may be powerful in reducing anxiety and providing reassurance that has an important impact on symptom severity $(19,20)$.

\section{INSERT TABLE 1}

\section{Non-pharmacological interventions}

This term encompasses a very wide range of interventions that range from those delivered by technology (e.g. neuromuscular electronic stimulation, NMES, the handheld fan) to psychological approaches. It also includes many which may be considered as originating outside routine clinical practice e.g. dancing, singing.

There are four recent Cochrane reviews under review or in progress by Bolzani et al on the non-pharmacological approaches that have been used in 
breathlessness (21-23). These reviews replace Bausewein et al's 2008 single review of all interventions with interventions now grouped as (i) cognitive emotional (ii) physical (iii) respiratory and (iv) multidimensional demonstrating the developing evidence base in this area (24). The groupings follow potential mechanisms of action discussed below in the 'Breathing, Thinking, Functioning' model.

Many trials of non-pharmacological interventions are under-powered and may not be adequately randomised or balanced, many have only been tested in patients with COPD so definitive guidance is lacking. However, many of these interventions have a low level of adverse effects (e.g. singing, Tai Chi) and high face validity for improving other aspects of general health - e.g. social contact and/or self-efficacy and have some elements (e.g. gentle exercise in Tai Chi) which suggest they may be helpful for a breathless individual. They may be recommended on those grounds. The core interventions, with available evidence are shown in Table 2.

\section{INSERT TABLE 2}

\section{Changing terminology - using drug-free interventions, a positive synonym}

The term 'non-pharmacological interventions' itself is unhelpful. It is used to describe a hugely varied group of treatment approaches varying from those with strong evidence (e.g. exercise) to some which are currently seen as having general health benefits perhaps through a predominantly social effect (not provided by clinical services and variably recommended by them). There is almost no limitation in what can be included under this umbrella term. Many interventions remain poorly investigated and their use based on best clinical practice and anecdote, hence the importance of Bolzani et al's imminent reviews to guide both research and clinical practice. Clinicians need not be deterred from suggesting that patients may like to try interventions that will not hurt, may have health-building social and self-efficacy benefit (e.g. singing in a choir) which have minimal or no evidence as yet.

Using the term non-pharmacological categorises these interventions simply by what they are not and gives no indication of how they may work to reduce breathlessness. Clinicians who are used to their primary interventions being pharmacological will not be inspired to use a poorly defined, negatively categorised group of interventions, with 'no evidence.' A term that inspires hope in patients and 
conviction in clinicians is needed, and the core interventions with the best evidence base actively promoted. Most non-pharmacological interventions act through a number of mechanisms to produce their effects, all ultimately also reduce breathlessness through reduction in central perception of both the severity of and the distress caused by the symptom. Finding a term that reflects this range of potential health benefits would help encourage use of these interventions. The term drug-free interventions is a synonym of non-pharmacological, which may be useful in presenting and emphasising the importance of this group of interventions which may, like exercise, have many potential benefits and few adverse effects.

In many areas of prescribing (e.g. antibiotics for minor virus infections) there are difficulties when drugs are withheld without a positive alternative given to patients. The importance of individualised education and the manner in which the intervention is introduced seems central to acceptability and concordance when using a drug-free intervention. One approach is discussed below.

\section{The Breathing, Thinking, Functioning (BTF) clinical model}

It is important to remember that the severity of breathlessness experienced by a patient is not only a function of the severity of the underlying lung condition (25). The BTF clinical model is useful in explaining how emotional and behavioural reactions to the feeling of breathlessness can inadvertently worsen the symptom (26). Three predominant vicious cycles of understandable, but unhelpful, reactions can occur.

\section{Insert figure 1 here}

\section{The Breathing Cycle}

Breathless patients experience a sense of 'needing more air', leading to an increased respiratory rate, higher ratio of inspiratory to expiratory length, and overuse of accessory or upper chest muscles. Such dysfunctional breathing patterns reduce the efficiency of breathing, and worsen the sense of breathlessness (27). If this is the predominant cycle the clinician might focus on the fan and breathing exercises as the initial interventions. 


\section{The Thinking Cycle}

The anxiety caused by breathlessness can, in turn, augment symptom perception, initiating a vicious cycle that can lead to a sense of panic (28). Panic is often contagious, and helping the patient and carer to be involved in developing a 'ritual for crises' may be helpful. Cognitive approaches, education and anxiety reduction techniques are also valuable.

\section{The Functioning Cycle}

The natural inclination to avoid the unpleasant experience of breathlessness causes a reduction in activity and associated deconditioning. This leads to a spiral of worsening breathlessness and disability (29). Supporting patients with structured incremental increases in activity can help break this vicious cycle.

The BTF model helps patients, carers and health professionals understand that there is potential to improve breathlessness, even when the cancer is incurable. With adequate explanation patients can see that, with a small change, a vicious cycle can be turned into a 'cycle of improvement' conferring large benefit. Such insight can be motivating and enhances self-efficacy.

Breathlessness interventions, discussed in this article, can appear complex, with the seemingly unlimited range of interconnected, multimodal nonpharmacological approaches making it difficult to know where to start $(19,30,31)$. The BTF model supports intervention delivery by explaining the value of nonpharmacological techniques which, unlike drug therapies, address the specific factors worsening an individual's symptom; by engaging patients and, indeed, healthcare staff, and carers, in symptom self-management; and by supporting the focus of the complex intervention towards those techniques most likely to be helpful, countering the predominant cycle(s) for that individual patient $(26,32)$.

\section{Insert figure 2 here}

\section{The Respiratory Distress Symptom Cluster and Quality of Life}

There is a growing acknowledgement that symptoms frequently co-occur in 'symptom clusters' and that understanding these clusters may improve the management of unrelieved symptoms in patients. Work in this area has been 
conducted in lung cancer symptomatology. Common and distressing symptoms of breathlessness, cough and fatigue are a major concern for many patients at all stages of lung cancer. For example, breathlessness is a serious symptom occurring in up to $90 \%$ of people with lung cancer, cough occurs in $47-86 \%$, and for some patients it can be more distressing than breathlessness, and patients report fatigue as one of the most important and distressing symptoms related to cancer and its treatment, prevalence is between 50-90\% (33-35). Unsurprisingly, patients often experience multiple symptoms and previous work has shown that these three symptoms are closely related with each other forming a symptom cluster, called the Respiratory Distress Symptom Cluster; patients with one will often suffer from one or both of the others (34). This has implications for symptom management, as potentially all three symptoms need to be managed concurrently if we are to observe any optimal improvements in overall symptom experience. Identification of this symptom cluster led to the development of a complex intervention consisting of a range of non-pharmacological techniques: controlled breathing and relaxation; acupressure and cough easing techniques - called the Respiratory Distress Symptom Intervention (RDSI). A multi-site randomised feasibility trial demonstrated the acceptability and efficacy of RDSI (36). For that trial, nurses and physiotherapists were trained and seconded from clinical practice to deliver the intervention as trial researchers. A fully powered phase III clinical trial is currently underway (https://clinicaltrials.gov/ct2/show/NCT03223805). For this study, nurse and physiotherapist clinicians are trained to delivery RDSI as part component of their normal practice and as trial researchers. The aim is to mirror clinical practice as much as possible in order to evaluate the real-world clinical and cost-effectiveness of RDSI.

\section{Individual interventions - exercise}

Exercise-centred interventions include but are not limited to: physical exercise and activity, the provision of appropriate mobility aids, neuromuscular electrical stimulation (NMES), facial cooling via a handheld fan, breathing exercises, as well as positioning and recovery advice (24). 
Breathlessness tends to lead to physical inactivity, irrespective of the underlying cause, which, in turn, can precipitate a downward spiral of disease (37) (see figure 3, 'The Spiral of Disability'). The unpleasantness of exertional breathlessness associated with cancer often results in patients reducing their physical activity to reduce the unpleasantness, leading to muscle deconditioning that drives further breathlessness at lower levels of activity which leads to an unhealthy spiral of reduced activity and increased deconditioning. The primary purpose of encouraging and supporting physical exercise and activity is to help counter this downward spiral, and help the patient maintain their function despite the symptom (38).

\section{INSERT FIGURE 3 HERE}

\section{Exercise and Neuromuscular Electrical Stimulation (NMES)}

A prerequisite to encouraging exercise and physical activity in the breathless patient is the assurance that being breathless is itself not dangerous, even though it can provoke anxiety, in those with illness. Breathlessness is a normal exertional response, and will settle with rest. Even following incremental exercise to a symptom-limited maximum, breathlessness in people with lung cancer usually recovers within a few minutes (39). As an exertional symptom, it is also useful to acknowledge that an improvement following treatment for breathlessness may present as the patient returning to meaningful physical activity, and not necessarily reporting a reduction in breathlessness intensity. In clinical practice, a question such 'what are you able to do now?' may be more relevant than 'how breathless are you?' The American Thoracic Society provide a helpful framework to classify outcome measures for breathlessness, consisting of three domains: 'sensory-perceptual experience'; incorporating what breathing feels like to the patient; 'affective distress' which may include the unpleasantness experienced during breathing; and 'symptom impact or burden' which might include functional ability (4). Outcome measures that consider the affective or impact domains of breathlessness (e.g. field walking tests, health status questionnaires) are often more responsive than those considering only the sensory domain (e.g. numerical rating or visual analogue scales) (40). 
There is a strong evidence base demonstrating that exercise training can improve levels of aerobic fitness and muscular performance among people living with and cured of cancer (41). As the downward spiral of disease involves physical inactivity, an exercise approach typically targeting lower limb function to support mobility, which also supports social participation, is helpful. Breathlessness can sometimes limit upper limb activities, e.g. cleaning, cooking and carrying shopping, as the muscles around the shoulder have a dual role to support breathing and for posture / stability during activities $(42,43)$. By improving physical capacity, the level of exertion for any given physical task or activity relative to capacity becomes proportionally lower, and the level of perceived exertion and symptoms, e.g. breathlessness and fatigue, is reduced. Where studies have measured breathlessness at 'isowork' following exercise training, the level of reported breathlessness is reduced, i.e. patients who have trained may have the same ultimate level of breathlessness but reach it at a higher level of exertion.

Exercise programmes have been studied across many conditions and settings (44). However, rates of uptake and completion vary widely, and benefit from intensive, supervised exercise training may be limited to selected patients, often those who are fitter and less symptomatic (45). Lower intensity programmes for example using interval, unilateral, or chair based exercise training compare well to aerobic training with respect to improving breathlessness and may be more appropriate for people with cancer $(46,47)$.

Unsupervised approaches include home-based training through written instruction or neuromuscular electrical stimulation (NMES) (48). NMES training improves lower limb muscle performance using a hand-held device that passes a low current through the muscle causing it to contract and so may be considered a form of passive exercise. NMES does not provoke the same exertional response as aerobic or weight training, so it can be particularly suited to the severely breathless patient. Again, the target is to prevent or slow the downward spiral that can affect the breathless patient, not to reduce breathlessness directly. In advanced disease, 18 studies (933 participants) in chronic respiratory disease, heart failure, and/or thoracic cancer have been reported comparing NMES to resistance training, sham, or no treatment. Overall, NMES led to a statistically significant improvement in quadriceps muscle strength as compared to control equating to approximately $1.1 \mathrm{~kg}$, and an 
improvement in exercise performance dependent on the test use (48). Self-reported breathlessness during daily life significantly improved following NMES in 2 of 4 studies, and breathlessness at isowork during a walking test was significantly reduced following NMES in 1 of 2 studies (48). In meta-analyses the most impaired patients tend to respond most favourably in terms of relative gains in strength and exercise performance, supporting its use in the most breathless patients (48). In studies specific to patients with thoracic cancer, a small pilot study found nonsignificant changes favouring NMES in quadriceps strength, daily step count, and exercise performance, whilst a feasibility study found low adherence to NMES alongside palliative chemotherapy $(49,50)$.

The ability, including the confidence, to exercise more has the potential to improve quality of life by enabling the breathless person to participate more in family life and activities, to reduce a feeling of dependency and helplessness and may even enable the person to be at home for longer because of this (51).

Supported exercise can be organized through hospice day centres (variable provision across UK) and exercise at home by breathlessness services (see below). Mobility aids are an evidence-based way of encouraging people to increase their level of exercise and again, may increase quality of life through their impact on confidence and a feeling of security (24). When doing a complicated activity (e.g. a day out) the individuals may pace themselves by planning to walk only some of the time, knowing that they can be supported in e.g. a wheelchair when needed. The only barrier to their use, reported by clinicians, is that younger patients may feel stigmatised ("that's for old people") or think that the clinician has not understood that the problem is related to their lungs, not their legs. Lending mobility aids out or using them for a while in a gym sometimes overcomes these hesitations.

There are many other health benefits to the individual from exercise, though most will be important only in those living with and beyond cancer. Exercise is known to have a beneficial effect on mood and morale, lead to a reduction in the incidence of cancer recurrence and Alzheimer's disease, a reduction in obesity and an increase in cardiovascular fitness (52-54). Encouraging exercise in the carer of the patient may help them to have better psychological health, encourage social connections outside the home as well as improve health for the stresses of caring. 


\section{The Hand-held Fan and Facial Cooling}

There is now good evidence that facial cooling with a hand-held fan in the area subserved by second and third branches of the trigeminal nerve, reduces the central perception of breathlessness (55-59). One recent controlled cross-over trial was specifically in people with lung cancer and showed a significant reduction in the feeling of dyspnoea $(p=0.003)$ measured on the modified Borg Scale, when the fan was used in combination with diaphragmatic breathing, compared with the latter used alone (57). The physiological mechanism of the reduction in breathlessness from facial cooling is not yet understood but its impact on the psychological health of breathless individuals has been demonstrated in a number of mixed methods studies synthesised by Luckett and colleagues (60).

The hand-held fan may be the best demonstration of how an apparently simple drug-free intervention can have multiple helpful impacts. There is some evidence that cancer-related breathlessness is not only related to exertion and may seem inexplicable and therefore unmanageable to an individual $(61,62)$. This in turn can raise anxiety, which again heightens the possibility of breathlessness.

If a patient is given a hand-held fan and shown how to use it with the theories behind its mechanisms of action explained (outlined below), their perception can change from being helpless in the face of sudden inexplicable breathlessness to having a tool to manage it $(55,60,63,64)$. The fan is a cheap, easily obtained, everyday piece of equipment which is not stigmatising (unlike oxygen tubing) and is light and portable (65). This means the patient can usually afford to have more than one, can take it wherever they go, and use it immediately they feel breathless. The fan is working not only through its effect on cooling nasal receptors and attenuating signals to the breathing centre in the brain stem but, it is likely, through an increase in the sense of self-efficacy. Increased self-efficacy, is known to reduce the incidence of depression and lead to better medical outcomes in those with chronic illness (32,66-69).

Episodic breathlessness, like episodic pain, is particularly difficult to manage the fan may be a useful tool here (70). A recent study has shown that episodic breathlessness is highly associated with feelings of panic, which often stem from feelings of loss of control (71). 
By feeling safer when more mobile, patients will obtain the benefits of being fitter whilst their disease is stable. The fan is also helpful for carers to initiate when the patient is breathless: standing by watching someone being breathless without being able to help is extremely stressful and distressing $(19,72)$. The fan can be a helpful part of 'ritual for crises' designed with patients and families for use during episodes of breathlessness. They have long be used for this as a core intervention in the Cambridge Breathlessness Intervention Service $(19,64,72)$.

Short burst oxygen therapy is rarely indicated in people with cancer-related breathlessness unless there is severe hypoxaemia at rest or on exertion, most people will receive better symptom control from using a hand-held fan. An early randomised controlled trial of oxygen versus air in cancer-related breathlessness showed that both reduced the sensation, and that the reduction was not dependent on relief of any baseline hypoxaemia(59). This suggests that the mechanism of reduction is similar to that postulated for the fan - the passage of cool air over nasal and facial receptors. Oxygen may be required in some for the correction of severe hypoxaemia but not for the palliation of breathlessness where hypoxaemia is mild.

\section{Activity Pacing - balancing rest and activity.}

Patients benefit from advice regarding moderating activity levels in accordance with their energy levels $(73,74)$. However, there remains a lack of robust research into the effectiveness of activity pacing as a standalone intervention for breathlessness. Favourable outcomes for multifaceted intervention programmes, such as pulmonary rehabilitation, which include pacing advice, are well documented. Attempts to research pacing specifically have found that it is poorly defined, open to varied interpretation and consequently difficult to evaluate (75).

Breathlessness is often correlated with fatigue and both symptoms are strongly associated with poor clinical outcomes (76). Pacing has been more widely researched in the management of conditions in which fatigue is one of the most prevalent symptoms, which includes cancer and others such as chronic pain and chronic fatigue. The principles of pacing for such conditions or symptoms can be appropriately applied to people experiencing breathlessness. 
Pacing involves adapting behaviour to maximise the use of energy available and avoiding extremes of rest or activity. It is a frustrating process as it necessitates an invariably unwanted change in well-established routines. Andrews et al have suggested that avoidance or endurance are both associated with poorer clinical outcomes (74). This supports advice given in many self-management programmes, such as the Macmillan HOPE programme, to avoid "boom or bust" where patients use up all energy by pushing themselves too much, then requiring a prolonged period of recovery (77).

\section{Insert figure 4}

Combining assessment and education about pacing can be part of education about increasing physical activity. This is relatively straightforward in those who are recovering from treatment that will improve their prognosis (as they will be become fitter and fitter) but more complex in people who are going to deteriorate at some point in the future. Making people more aware of their deterioration by measuring decline or otherwise making it very apparent will not help morale, whilst being as active as possible for as long as possible will. These two aims need to be kept in mind. Encouraging exercise and pacing are complementary in ensuring the achievement of optimum fitness. They are key aims to be kept in mind.

Comprehensive individual assessment and analysis of activity is fundamental and carried out extensively by occupational therapists. Pacing advice is a priority when the 'functioning' cycle is particularly dysfunctional.

\section{Breathing Techniques for breathlessness in cancer}

Breathing pattern manipulation in the form of breathing techniques or exercises were included in early studies of complex interventions for cancer-related breathlessness and continue to form a core component of standard complex interventions, with breathing control (BC) and diaphragmatic breathing (DB) the two most commonly used techniques $(9,19,78-80)$. It has been hypothesized that they improve the efficiency of ventilation, therefore reducing the work of breathing (81). The terms BC and DB are sometimes used interchangeably in practice, yet they are given different definitions in respiratory physiotherapy guidelines (82). DB prolongs and slows inspiration, deliberately increases tidal volume, whereas BC maintains 
normal tidal breathing with relaxed upper chest and shoulders $(82,83)$. Whether BC or DB is more effective for breathlessness in cancer has not been investigated. Yet in non-malignant conditions, such as severe COPD, deliberate increase in inspiratory volume, as in DB, may worsen dynamic hyperinflation, creating asynchronous rib movement and uneven distribution of air, therefore increasing work of breathing and breathlessness $(82,84,85)$. However a more recent Cochrane review found in favour of DB, even in severe COPD, as a method of increasing walking distance, although the effect on breathlessness was variable (83). No studies have investigated the effectiveness of a standalone breathing technique in people with cancer and more research is required.

Pursed-lips breathing (PLB), breathing out through narrowed lips as if flickering a candle, has recently been described as a technique to ease breathlessness in those with cancer (86-88), suggesting that benefit may have been observed in clinical practice, although there have been no studies on its effectiveness. PLB is often done instinctively in those with severe COPD (89). In obstructive respiratory disease PLB is thought to reduce breathlessness by producing $5 \mathrm{cmH}_{2} \mathrm{O}$ pressure at the lips, supporting airways and improving expiratory flow, therefore reducing dynamic hyperinflation and allowing subsequent improvement in tidal volume (90-92). Although this breathing technique has not been investigated in malignant disease, findings in COPD suggest that PLB will have no effect or worsen breathlessness in the absence of significant dynamic hyperinflation (93).

Dysfunctional breathing is a chronic abnormal breathing pattern, with or without hyperventilation, and may create breathlessness apparently disproportionate to disease severity (94). Excessive accessory muscle use and upper chest dominance is the most common dysfunctional pattern (95). Prevalence of dysfunctional breathing has been found to be as high as $9.5 \%$ of the general population, up to $29 \%$ in those with asthma, and approximately $50 \%$ in those with COPD $(27,96,97)$. Those with cancer may experience shock, stress, fear, panic, worry and uncertainty putting them at risk of dysfunctional breathing due to chronic psychological stress $(98,99)$. Dysfunctional breathing may reduce efficiency of ventilation, increase work of breathing and therefore exacerbate breathlessness and should be considered if breathlessness in all breathless patients with cancer(100). 
This is an emerging area of interest with no studies on the prevalence or management in cancer so far.

\section{Psychological Interventions}

Distress can be expressed by physical symptoms or exacerbate physical symptoms; anxiety and dyspnea are inextricably linked through the CNS.

Cancer services are now underpinned by knowledge of the importance of psychological care. The link between psychological distress and symptom severity is not always recognized in clinical practice, however. For example, clinicians may be taught the disease-related causes of breathlessness but not the neurophysiology that produces the symptom. The concept that breathlessness is peripherally generated (e.g.by direct effects of tumour) but centrally processed by the thinking and feeling areas of the CNS is not widely recognised amongst clinicians.

Specific treatment for anxiety, frustration, depression generated by the losses imposed by severe breathlessness, or the fear and anxiety generated by the feeling of being breathless itself, or the cognitions it provokes (e.g. 'I'm going to die desperate to get my breath') are not addressed in standard approaches to symptoms which tend to focus on the underlying physical pathophysiology $(19,31,101,102)$ The fear of the carer, left to manage their loved one alone, without understanding how they can help, is a common reason for out-of-hours use of clinical services. Without understanding the central generators, exacerbators or perpetuators of breathlessness, the clinician may not understand why an individual's breathlessness is so severe.

The therapeutic effect of being able to discuss the fears and limitations associated with breathlessness with a professional who has specific expertise, who can give personalised advice and education on self-management, has been shown to be more effective than standard care in people with cancer $(19,31,72)$. This impact underlines the importance of access to a specialist breathlessness service (see below) or palliative care service at least, for people who have 'difficult' or intractable breathlessness.

Recent research has demonstrated the value of building resilience in people with cancer, as protective against emotional distress and improved quality of life in living 'with and beyond cancer.' Encouraging and supporting physical and mental 
activity and social participation is always part of this. The 'five ways to wellbeing' framework is a valuable tool in helping patients and carers to understand about broader health-building actions they can take themselves, valuable, even in the face of life-limiting disease (103). Reducing the focus on directly managing breathlessness for some of the time and considering positive health-building steps may have value in improving quality of life.

\section{Caring for Carers}

There is increasing awareness of the important role informal carers (family or friends in an unpaid role) play in supporting patients living with breathlessness, and the impact of this on their own health and wellbeing $(104,105)$. Supporting someone with advanced cancer who is breathless is frightening and restricting - it is a source of severe anxiety and carers feel helpless and powerless due to a lack of knowledge and confidence in managing breathlessness (62). Educating carers about breathlessness could increase carer confidence and help patients to better selfmanage their breathlessness, potentially reducing admissions (106). Yet we lack evidence-based educational interventions for carers of patients with breathlessness and there is limited involvement of carers in clinical contacts relating to breathlessness management and education $(106,107)$. Carer engagement in the multi-disciplinary Cambridge Breathlessness Intervention Service resulted in positive impacts such as reduced fear, anxiety, worry and panic, and greater confidence about breathlessness, with some carers living separately from patients reported receiving fewer patient phone calls (19). Joint education with patients, giving practical advice, and strategies for helping patients has been advocated in a range of settings, and specific topics carers might want to learn about in relation to breathlessness have been identified $(106,108)$. Alongside such breathlessnessspecific education there is a need to identify and address carers other support and health needs and mechanisms to achieve this have been identified (104).

\section{Breathlessness Services}

Over the last 15 years, breathlessness services have been developed and evaluated to support patients with advanced disease in managing their 
breathlessness, by delivering an individualised complex intervention. The first service was the Cambridge Breathlessness Intervention Service (CBIS) built on a nurse-led intervention investigated by Corner and Bredin $(72,79,80)$. Breathlessness services offer the whole scope of non-pharmacological and pharmacological interventions for patients who have persisting breathlessness despite optimal management of their underlying disease, as part of a complex intervention after a detailed individual and family assessment.

The core interventions of most services tend to be those with the greatest evidence base, i.e. use of the hand-held fan, airways clearance and cough minimisation techniques, distraction techniques, psychological support, anxiety management, an individualised exercise plan, e.g. a home programme of exercise delivered by a personalised sheet with a DVD, and/or advice on activity management and energy conservation strategies like pacing $(9,19,31,36,79,109,110)$. Breathing exercise training is routinely used too, although specific evidence for people with cancer is lacking $(9,111)$.

In a breathlessness service, unlike a fixed group programme, these interventions are tailored to the individual needs of patients and also provide support to carers. Various models of breathlessness services have evolved either more clinic, hospice or home based. The detailed assessment may be considered part of the therapy with development of what is called a therapeutic alliance in the psychotherapy literature. The temptation for clinical managers is to reduce breathlessness management to a series of individual tasks without detailed assessment, so that it can be offered more cheaply.

Multi-professional teams offering the service comprise doctors, physiotherapists and occupational therapists (most commonly) but also nurses, social workers and psychologists. Where a professional is not funded to work on the team, access to them through partnership with another department may be organised. Allied Health Professionals, (AHP) particularly physiotherapists, occupational therapists and speech and language therapists are particularly well placed to help the large numbers of people with cancer-related breathlessness. The focus of their work and training) is always about improving self-management. Breathless patients may be referred to them for other reasons (e.g swallowing difficulties, concerns about safe discharge, mobility issues) and the breathlessness may not have been detected before referral. However not all AHPs have training in 
how to manage this very common problem and so opportunities to improve care may be lost. Ensuring that breathlessness management is a core part of AHP training could have a beneficial impact on a significant number of patients with cancerrelated breathlessness at an earlier stage.

Breathlessness services have two important features that may be crucial for people with cancer- (i) improving the management of breathlessness and (ii) providing early access to palliative care. Those which are physician-led also include individual assessment, medical review and developing individualised management plans $(19,31,109)$. These physician-led models have mainly been developed by two groups in Cambridge and London in the UK working closely together. Physician-led models differ in respect to the intervention being interdisciplinary, i.e. palliative and respiratory medicine consultants working closely together, such as in BSS, or the wider palliative medicine team as in CBIS. Some services provide predefined sessions delivered by nurses or therapists to the patients either individually or in a group setting $(9,36,110)$. Bredin's model, one of the first in its kind, combined elements of both (79). It was nurse-led but included individual assessment and goal setting: there were high levels of attrition as the patients needed to attend hospital to receive the treatment.

Overall, the evidence base for the effectiveness of breathlessness services is increasing and they will hopefully become part of the health care system to support patients suffering from breathlessness and advanced disease $(19,31,109)$.

The breathlessness services developed so far also have an important role in research in breathlessness and teaching and supporting other clinicians managing patients with this frightening symptom. They do not look after patients for the longerterm but focus on detailed assessment and symptom management and then work in partnership with other services. In patients with advanced cancer, these will be palliative care, oncology or primary care services.

Once treatment has been started in people with cancer, continuing, frequent reassessment is essential particularly in those with a poor prognosis. Pharmacological management will almost always be needed at some point, sometimes at the first assessment. (112-114) and patients should not be persist with drug-free treatments that were once helpful but have become too onerous. 


\section{Conclusions}

Every clinician who looks after breathless patients should know about the drug-free interventions for breathlessness discussed here. They need to ask about breathlessness routinely, assess its severity, and, where present initiate the interventions they can (e.g. the fan) to provide some relief rapidly. They then need to know who can provide specialist complex interventions in their locality and refer as necessary. The use of a concise validated outcome scale like the D12 will help continuing management.

The very first step in helping breathlessness, assessing it routinely, is often omitted leaving the symptom unrecognised and without specific treatment $(12,115)$. Assessment is part of treatment, recognition and validation of breathlessness seems to be therapeutic (72). The 'invisibility of breathlessness' has been described by Gysels and Higginson in people with COPD (116). Many people with lung cancer have had COPD and the invisibility of the symptom, in spite of the major distress it causes, persists. This may in part stem from clinicians' uncertainty of how to manage it, leading to a reluctance to elicit it (17).

With the availability of evidence-based treatment it is now critical to heighten awareness of this distressing symptom in clinicians, trainees and students and equip them with the knowledge of how to assess breathlessness and start treatment. Specialist breathlessness services need to connect with clinicians treating significant numbers of people with the symptom so that interventions are given earlier, reducing suffering for patients and families. There are encouraging signs that this is happening but the pace is too slow $(117,118)$.

The BTF model can be used to facilitate the assessment for, and provision of drug-free interventions (26). Its effectiveness as an educational tool for both patients and clinicians is undergoing further evaluation in different settings.

Although there have been many advances in both the recognition and management of breathlessness as a symptom, many people still do not get the support they need and continue to suffer, invisibly, with this devastating and frightening symptom. We need to increase and refine the evidence we have for managing breathlessness, particularly in people with cancer, however we do now have some tools: it really is time to use them. 


\section{Expert Commentary:}

The definitive Cochrane reviews of non-pharmacological interventions will be published (21-23) soon. These will highlight the evidence-based interventions currently available for breathlessness. It is likely that better evidence for the huge range of low risk interventions which may be very valuable (e.g. music therapy) but which are variably available, will still be required. We also need better understanding of the 'final common pathway' of modifying central perception of breathlessness to expand the range of therapies available and provide personalized breathlessness treatment.

Uptake of all new interventions is slow even with drug therapy. Introducing new interventions which both require behaviour change and are drug free, compounds the difficulties of their routine introduction. More research into effective implementation of behavior change is needed.

\section{General health}

It is becoming clear that psychological resilience may be improved even when an individual is going to die or live a very restricted life with progressive disease (119-123). The promising effects of reducing the severity of anxiety and depression and increasing a sense of agency by enabling people to self manage their symptoms may soon make some form of 'resilience training' a routine part of cancer and palliative care, even when the patient has a short prognosis (120-124).

Wellbeing interventions are hopeful interventions, not dishonest ones. If the person who dies is less distressed this will have an impact on those closest to them who survive. Care of this group is likely not only to reduce their psychological distress but also reduce complex grief reactions, long known to predispose people to depression and difficulties with making and maintaining intimate relationships in the longer-term (125-127).

The research area of resilience training is burgeoning in the literature around cancer - but there is less interest in palliative care; understanding more about the 
applicability of 'resilience training' or wellbeing interventions for this group (patients and families) could lead to improvements in quality of life (128).

\section{The Inflammatory response}

The importance of the effect of the inflammatory response in the genesis of symptoms as well as disease and on the systemic feeling of 'wellness' and 'wellbeing' is becoming more widely appreciated. Reducing the inflammatory response in people with advanced cancer (and those closest to them as preventative treatment in hard-pressed carers) is also an area needing research in palliative care. There is emerging evidence suggesting that increasing wellbeing may reduce inflammation and this may also be important in symptom control $(122,129)$.

All these research priorities need multispecialty collaboration - including clinicians and academics in palliative care, oncology, basic scientists, imaging specialists, neuroscientists, social scientists and neuropsychologists.

\section{The Therapeutic Alliance}

The clinical importance of the assessment interview and the formation of a therapeutic alliance is an under researched area in palliative and supportive care. It is often observed that patients admitted to a hospice often feel better before there are changes in their drugs and that palliative care reduces stress in patients. These 'placebo effects' are likely to be mediated though central perception. If the content and mechanisms of these effects can be better understood they will be easier to teach as core skills of medical practice $(130,131)$.

\section{Five-year view}

Cancer medicine clinicians now aim to give personalised treatment based on the genetic characteristics of the tumour as well as the patient's disposition, fitness and treatment choices.

The personal psychosocial make up of each individual patient needs to be assessed and understood too, in order to give them the best personalized, drug-free treatment regimen. Within the next five years understanding the neuroscience of 
empathy and psychological interventions may help guide clinicians in how to give better, targeted psychosocial care that is more rapidly effective in relieving distress and anxiety. Neuroscience may also help clinicians to select the other most effective drug- free intervention regimen for a particular individual, including physical ones such as NMES.

The personal characteristics of the people delivering the interventions for breathlessness also play a part in their effectiveness. This impact seems to be mediated through the way in which interventions are used by clinicians. Kindness and empathy and a personal concern for the patient in the clinician as well as expert knowledge and a clear attention to the symptom of breathlessness for itself seem to be important (19).

The use of electronic records, electronic aids, on-line support and possibly 'artificial intelligence, may help to improve the proportion of patients in whom breathlessness is detected early, reassessed regularly and actively treated. It may help with monitoring remotely and getting help more quickly, or even supporting psychological interventions 'out of hours.' Driverless cars may also offer more freedom for breathless individuals. Decision support for clinicians may be useful in supporting the use of the current evidence base and improving the lives of patients with cancer and breathlessness and their families.

\section{Key issues}

- Breathlessness is a common, often terrifying, symptom that is almost ubiquitous in advanced cancer, and significantly erodes the quality of life of patient and family.

- It is essential to elicit the symptom routinely and actively, measure its severity, treat it appropriately and reassess treatment regimens regularly.

- The Breathing, Thinking, Functioning approach can be a useful way of helping patients, clinicians and carers understand a drug-free approach to managing breathlessness.

- Increasing or continuing exercise (where possible), breathing retraining, pacing and use of the hand-held fan should be considered for every patient. 
- Cough and fatigue usually co-exist in breathless people with cancer and need assessment and treatment.

- Non-pharmacological - drug free - treatments can play an important part in improving quality of life for breathless people with cancer and their families.

- Using the term drug-free may be one way of giving this large group of interventions a more positive feel, reflective of their effectiveness, to both patients and clinicians.

- Personalised treatments with drug-free interventions need to be as carefully targeted and reviewed as any other medical or surgical intervention, more work is needed on predictive factors that can guide this strategy in an individual.

- NMES seems to be a useful tool in those with the most advanced disease in whom exercise is most difficult.

- Family and friends who are carers of those with breathlessness suffer significant stress and need help and support themselves.

\section{References}

1. Booth $\mathrm{S}$, Wade R. Oxygen or air for palliation of breathlessness in advanced cancer. J R Soc Med. 2003;96(5):215-8.

2. Muers MF, Round CE. Palliation of symptoms in non-small cell lung cancer: a study by the Yorkshire Regional Cancer Organization thoracic group. Thorax. 1993;48(1):339-343.

3. Hayen A, Herigstad M, Pattinson KTS. Understanding dyspnea as a complex individual experience. Maturitas. 2013;76(1):45-50.

4. ** Parshall MB, Schwartzstein RM, Adams L, Banzett RB, Manning HL, Bourbeau J, et al. An official American thoracic society statement: Update on the mechanisms, assessment, and management of dyspnea. Am J Respir Crit Care Med. 2012;185:435-52.

5. Pattinson KTS, Johnson MJ. Neuroimaging of central breathlessness mechanisms. Curr Opin Support Palliat Care. 2014;8:225-33.

6. Zoumot Z, Davey C, Jordan S, McNulty WH, Carr DH, Hind MD, et al. A randomised controlled study of Bronchoscopic Lung Volume Reduction with endobronchial valves for patients with Heterogeneous emphysema and Intact interlobar Fissures: the BeLieVeR-HIFi study. Effic Mech Eval. 2015;2(5):1-34.

7. * Temel JS, Greer J a, Muzikansky A, Gallagher ER, Admane S, Jackson V a, et al. 
Early palliative care for patients with metastatic non-small-cell lung cancer. $\mathrm{N}$ Engl $\mathrm{J}$ Med. 2010;363(8):733-42.

8. Kloke M, Cherny N. Treatment of dyspnoea in advanced cancer patients: ESMO Clinical Practice Guidelines. Ann Oncol. 2015;26(Supplement 5):v169-73.

9. Johnson MJ, Kanaan M, Richardson G, Nabb S, Torgerson D, English A, et al. A randomised controlled trial of three or one breathing technique training sessions for breathlessness in people with malignant lung disease. BMC Med. 2015;13(1):213.

10. Currow DC, Smith J, Davidson PM, Newton PJ, Agar MR, Abernethy AP. Do the trajectories of dyspnea differ in prevalence and intensity by diagnosis at the end of life? A consecutive cohort study. J Pain Symptom Manage. 2010 Apr;39(4):680-90.

11. * Johnson MJ, Yorke J, Hansen-Flaschen J, Lansing R, Ekström M, Similowski T, et al. Towards an expert consensus to delineate a clinical syndrome of chronic breathlessness. Eur Respir J. 2017 May 1;49(5).

12. Banzett RB, O'Donnell CR. Should we measure dyspnoea in everyone? Eur Respir J. 2014;43:1547-50.

13. Stevens JP, Baker K, Howell MD, Banzett RB. Prevalence and predictive value of dyspnea ratings in hospitalized patients: Pilot studies. PLoS One. 2016;11(4):1-11.

14. Nishimura K, Izumi T, Tsukino M, Oga T. Dyspnea Is a Better Predictor of 5-Year Survival Than Airway Obstruction in Patients With COPD. Chest. 2002;121:1434-40.

15. Maltoni M, Priovano M, Scarpi E, Marinari M, Indelli M, Arnoldi E, et al. Prediciton of Survival of Patients Terminally III with Cancer. Cancer. 1995;75(10):2613-22.

16. Hellenkamp K, Darius H, Giannitsis E, Erbel R, Haude M, Hamm C, et al. The German CPU Registry: Dyspnea independently predicts negative short-term outcome in patients admitted to German Chest Pain Units. Int J Cardiol. 2018;181:88-95.

17. Roberts DK, Thorne SE, Pearson C. The experience of dyspnea in late-stage cancer. Patients' and nurses' perspectives. Cancer Nurs. 1993;16(4):310-20.

18. ** Tan JY, Yorke J, Harle A, Smith J, Blackhall F, Pilling M, et al. Assessment of Breathlessness in Lung Cancer: Psychometric Properties of the Dyspnea-12 Questionnaire. J Pain Symptom Manage. 2017;53(2):208-15.

19. ** Farquhar MC, Prevost a T, McCrone P, Brafman-Price B, Bentley A, Higginson IJ, et al. Is a specialist breathlessness service more effective and cost-effective for patients with advanced cancer and their carers than standard care? Findings of a mixedmethod randomised controlled trial. BMC Med. 2014;12:194.

20. Lucas $\mathrm{V}$, Booth $\mathrm{S}$. The importance of placebo effects in enhancing palliative care interventions. BMJ Support Palliat Care. 2014;4(2):212-6.

21. ** Bolzani A, Rolser SM, Kalies H, Maddocks M, Rehfuess E, Gysels M, et al. Physical interventions for breathlessness in adults with advanced diseases. Cochrane 
Database Syst Rev. 2017;(6):CD012684.

22. ** Bolzani A, Rolser SM, Kalies H, Maddocks M, Rehfuess E, Swan F, et al. Respiratory interventions for breathlessness in adults with advanced diseases. Cochrane Database Syst Rev. 2017;(6):CD012683

23. ** Bolzani A, Rolser SM, Kalies H, Maddocks M, Rehfuess E, Hutchinson A, et al. Cognitive-emotional interventions for breathlessness in adults with advanced diseases. Cochrane Database Syst Rev. 2017;(6):CD012682.

24. Bausewein C, Booth S, Gysels M, Higginson IJ. Non-pharmacological interventions for breathlessness in advanced stages of malignant and non-malignant diseases. Cochrane Database Syst Rev. 2008;2011(2).

25. Agusti A, Calverley PMA, Celli B, Coxson HO, Edwards LD, Lomas DA, et al. Characterisation of COPD heterogeneity in the ECLIPSE cohort. Respir Res. 2010;11:122.

26. ** Spathis A, Booth S, Moffat C, Hurst R, Ryan R, Chin C, et al. The Breathing, Thinking, Functioning clinical model: a proposal to facilitate evidence-based breathlessness management in chronic respiratory disease. npj Prim Care Respir Med. 2017;27(1):27.

27. Thomas M, McKinley RK, Freeman E, Foy C. Prevalence of dysfunctional breathing in patients treated for asthma in primary care: cross sectional survey. BMJ. 2001;322(7294):1098-100.

28. Livermore N, Butler JE, Sharpe L, McBain RA, Gandevia SC, McKenzie DK. Panic Attacks and Perception of Inspiratory Resistive Loads in Chronic Obstructive Pulmonary Disease. Am J Respir Crit Care Med. 2008;178(1):7-12.

29. Kim HC, Mofarrahi M, Hussain SNA. Skeletal muscle dysfunction in patients with chronic obstructive pulmonary disease. Int J Chron Obstruct Pulmon Dis. 2008;3(4):637-58.

30. Craig P, Dieppe P, Macintyre S, Michie S, Nazareth I, Petticrew M, et al. Developing and evaluating complex interventions: the new Medical Research Council guidance. BMJ. 2008;337:a1655.

31.** Higginson IJ, Bausewein C, Reilly CC, Gao W, Gysels M, Dzingina M, et al. An integrated palliative and respiratory care service for patients with advanced disease and refractory breathlessness: a randomised controlled trial. Lancet Respir Med. 2014;2(14):979-87.

32. de Silva D. Helping people help themselves. The Health Foundation. 2011.

33. Edmonds P, Higginson I, Altmann D, Sen-Gupta G, McDonnell M. Is the presence of dyspnea a risk factor for morbidity in cancer patients? J Pain Symptom Manage. 2000;19(1):15-22. 
34. * Molassiotis A, Lowe M, Blackhall F, Lorigan P. A qualitative exploration of a respiratory distress symptom cluster in lung cancer: Cough, breathlessness and fatigue. Lung Cancer. 2011;71(1):94-102.

35. Hofman M, Ryan JL, Figueroa-Moseley CD, Jean-Pierre P, Morrow GR. CancerRelated Fatigue: The Scale of the Problem. Oncologist. 2007;12(suppl_1):4-10.

36. ** Yorke J, Lloyd-Williams M, Smith J, Blackhall F, Harle A, Warden J, et al. Management of the respiratory distress symptom cluster in lung cancer: a randomised controlled feasibility trial. Support Care Cancer. 2015;23(11):3373-84.

37.* Maddocks M, Hopkinson J, Conibear J, Reeves A, Shaw C, Fearon KCH. Practical multimodal care for cancer cachexia. Curr Opin Support Palliat Care. 2016;10(4):298305.

38. Man W, Donaldson M, Maddocks D, Martolini MI, Polkey M. Muscle function in COPD: a complex interplay. Int J Chron Obstruct Pulmon Dis. 2012;7:523.

39. * Maddocks M, Taylor V, Klezlova R, England R, Manderson C, Wilcock A. When will I get my breath back? Recovery time of exercise-induced breathlessness in patients with thoracic cancer. Lung Cancer. 2012;76(1):128-9.

40. Wadell K, Webb KA, Preston ME, Amornputtisathaporn N, Samis L, Patelli J, et al. Impact of Pulmonary Rehabilitation on the Major Dimensions of Dyspnea in COPD. COPD J Chronic Obstr Pulm Dis. 2013;10(4):425-35.

41. * Silver JK, Baima J, Mayer RS. Impairment-driven cancer rehabilitation: An essential component of quality care and survivorship. CA Cancer J Clin. 2013;63(5):295-317.

42. Jolley CJ, Moxham J. A physiological model of patient-reported breathlessness during daily activities in COPD. Eur Respir Rev. 2009;18(112):66-79.

43. Celli BR, Rassulo J, Make BJ. Dyssynchronous breathing during arm but not leg exercise in patients with chronic airflow obstruction. N Engl J Med. 1986;314(23):1485-90.

44. Williams M. Applicability and generalizability of palliative interventions for dyspnoea: one size fits all, some or none? Curr Opin Support Palliat Care. 2011;5(2):92-100.

45.* Maddocks M, Mockett S, Wilcock A. Is exercise an acceptable and practical therapy for people with or cured of cancer? A systematic review. Cancer Treat Rev. 2009;35(4):383-90.

46. Talbot Rice H, Malcolm L, Norman K, Jones A, Lee K, Preston G, et al. An evaluation of the St Christopher's Hospice rehabilitation gym circuits classes: Patient uptake, outcomes, and feedback. Prog Palliat Care. 2014;22(6):319-25.

47. Sachs $S$, Weinberg RL. Pulmonary rehabilitation for dyspnea in the palliative-care setting. Curr Opin Support Palliat Care. 2009 Jun [cited 2017 Dec 6];3(2):112-9. Available from: http://www.ncbi.nlm.nih.gov/pubmed/19381095 
48. * Jones S, Man WD-C, Gao W, Higginson IJ, Wilcock A, Maddocks M. Neuromuscular electrical stimulation for muscle weakness in adults with advanced disease. Cochrane Database of Systematic Reviews. 2016; CD009419.

49. Maddocks M, Halliday V, Chauhan A, Taylor V, Nelson A, Sampson C, et al. Neuromuscular Electrical Stimulation of the Quadriceps in Patients with Non-Small Cell Lung Cancer Receiving Palliative Chemotherapy: A Randomized Phase II Study. Lucia A, editor. PLoS One. 2013;8(12):e86059. A

50. Maddocks M, Lewis M, Chauhan A, Manderson C, Hocknell J, Wilcock A. Randomized Controlled Pilot Study of Neuromuscular Electrical Stimulation of the Quadriceps in Patients with Non-Small Cell Lung Cancer. J Pain Symptom Manage. 2009;38(6):950-6.

51. Booth S, Adams L. The shuttle walking test: a reproducible method for evaluating the impact of shortness of breath on functional capacity in patients with advanced cancer. Thorax. 2001;56(2):146-50.

52. Hernández SSS, Sandreschi PF, da Silva FC, Arancibia BAV, da Silva R, Gutierres PJB, et al. What Are the Benefits of Exercise for Alzheimer's Disease? A Systematic Review of the Past 10 Years. J Aging Phys Act. 2015;23(4):659-68.

53. Stamatakis E, Lee I-M, Bennie J, Freeston J, Hamer M, O’Donovan G, et al. Does strength promoting exercise confer unique health benefits? A pooled analysis of eleven population cohorts with all-cause, cancer, and cardiovascular mortality endpoints. Am J Epidemiol. 2017 [epub ahead of print] https://doi.org/10.1093/aje/kwx345

54. Duncan M, Moschopoulou E, Herrington E, Deane J, Roylance R, Jones L, et al. Review of systematic reviews of non-pharmacological interventions to improve quality of life in cancer survivors. BMJ Open. 2017;7(11):e015860.

55. Galbraith S, Fagan P, Perkins P, Lynch A, Booth S. Does the use of a handheld fan improve chronic dyspnea? A randomized, controlled, crossover trial. J Pain Symptom Manage. 2010;39(5):831-8.

56. Bausewein C, Booth S, Gysels M, Kühnbach R, Higginson IJ. Effectiveness of a hand-held fan for breathlessness: a randomised phase II trial. BMC Palliat Care. 2010;9(1):22.

57. Puspawati NLPD, Sitorus R, Herawati T. Hand-held Fan Airflow Stimulation Relieves Dyspnea in Lung Cancer Patients. Asia-Pacific J Oncol Nurs. 2017;4(2):162-7.

58. Swan F, Booth S. The role of airflow for the relief of chronic refractory breathlessness. Curr Opin Support Palliat Care. 2015;9(3).

59. Booth S, Kelly MJ, Cox NP, Adams L, Guz A. Does oxygen help dyspnea in patients with cancer? Am J Respir Crit Care Med. 1996;153(5):1515-8. 
60. Luckett T, Phillips J, Johnson MJ, Farquhar M, Swan F, Assen T, et al. Contributions of a hand-held fan to self-management of chronic breathlessness. Eur Respir J. 2017;50(2):1700262.

61. ${ }^{*}$ Booth S. Science supporting the art of medicine: improving the management of breathlessness. Palliat Med. 2013;27:483-5.

62. Booth S, Silvester S, Todd C. Breathlessness in cancer and chronic obstructive pulmonary disease: using a qualitative approach to describe the experience of patients and carers. Palliat Support Care. 2003;1(4):337-44.

63. Cambridge Breathlessness Intervention Service; Cambridge University Hospitals NHS Foundation Trust. Patient Information Leaflet 2: Handheld fan. 2016. Available from: https://www.cuh.nhs.uk/breathlessness-intervention-service-bis/resources/patientinformation-leaflets

64. Booth S, Moffat C, Burkin J. The Cambridge Breathlessness Intervention Service Manual: Building a Breathlessness Service. 2011.

65. Arnold E, Bruton A, Donovan-Hall M, Fenwick A, Dibb B, Walker E. Ambulatory oxygen: Why do COPD patients not use their portable systems as prescribed? A qualitative study. BMC Pulm Med. 2011;11(1):9.

66. Hallas CN, Howard C, Theadom A, Wray J. Negative beliefs about breathlessness increases panic for patients with chronic respiratory disease. Psychol Health Med. 2012;17(4):467-77.

67. Deakin TA, McShane CE, Cade JE, Williams R. Group based training for selfmanagement strategies in people with type 2 diabetes mellitus. In: Steinsbekk A, editor. Cochrane Database of Systematic Reviews. 2005:CD003417.

68. Zwerink M, Brusse-Keizer M, van der Valk Paul D, Zielhuis Gerhard A, Monninkhof Evelyn M, van der Palen J, et al. Self management for patients with chronic obstructive pulmonary disease. Cochrane Database Syst Rev. 2014;(3):CD002990

69. Jovicic A, Holroyd-Leduc JM, Straus SE. Effects of self-management intervention on health outcomes of patients with heart failure: a systematic review of randomized controlled trials. BMC Cardiovasc Disord . 2006;6(1):43.

70. * Simon ST, Bausewein C, Schildmann E, Higginson IJ, Magnussen H, Scheve C, et al. Episodic breathlessness in patients with advanced disease: A systematic review. J Pain Symptom Manage. 2013;45(3):561-78.

71. Linde P, Hanke G, Voltz R, Simon ST. Unpredictable episodic breathlessness in patients with advanced chronic obstructive pulmonary disease and lung cancer: a qualitative study. Support Care Cancer. 2018;26(4):1097-104.

72. Booth S, Farquhar M, Gysels M, Bausewein C, Higginson IJ. The impact of a breathlessness intervention service (BIS) on the lives of patients with intractable 
dyspnea: a qualitative phase 1 study. Palliat Support Care. 2006;4(3):287-93.

73. Van Heest KNL, Mogush AR, Mathiowetz VG. Effects of a One-to-One Fatigue Management Course for People With Chronic Conditions and Fatigue. Am J Occup Ther. 2017:71(4): 7104100020p1-p9.

74. Andrews NE, Strong J, Meredith PJ. Activity Pacing, Avoidance, Endurance, and Associations With Patient Functioning in Chronic Pain: A Systematic Review and Meta-Analysis. Arch Phys Med Rehabil. 2012;93(11):2109-2121.e7.

75. Gill JR, Brown CA. A structured review of the evidence for pacing as a chronic pain intervention. Eur J Pain. 2009;13(2):214-6.

76. Cheville AL, Novotny PJ, Sloan JA, Basford JR, Wampfler JA, Garces YI, et al. The value of a symptom cluster of fatigue, dyspnea, and cough in predicting clinical outcomes in lung cancer survivors. J Pain Symptom Manage. 2011;42(2):213-21.

77. HOPE Programme. Coventry University. HOPE Cancer Research. 2017. Available from: https://hopeprogramme.coventry.ac.uk/hope/HOPE-Research.aspx

78. Greer JA, MacDonald JJ, Vaughn J, Viscosi E, Traeger L, McDonnell T, et al. Pilot Study of a Brief Behavioral Intervention for Dyspnea in Patients With Advanced Lung Cancer. J Pain Symptom Manage. 2015;50(6):854-60.

79. Bredin M, Corner J, Krishnasamy M, Plant H, Bailey C, A'Hern R. Multicentre randomised controlled trial of nursing intervention for breathlessness in patients with lung cancer. BMJ. 1999;318(7188):901-4.

80. Corner J, Plant H, A'Hern R, Bailey C. Non-pharmacological interventions for breathlessness in lung cancer. Palliat Med. 1996;10(4):299-305.

81. Ryan R, Spathis A, Booth S. Correlates between basic science and therapeutic interventions. Curr Opin Support Palliat Care. 2014;8(3):200-7.

82. Bott J, Blumenthal S, Buxton M, Ellum S, Falconer C, Garrod R, et al. Guidelines for the physiotherapy management of the adult, medical, spontaneously breathing patient. Thorax. 2009;64(Suppl 1):i1-52.

83. Holland AE, Hill CJ, Jones AY, McDonald CF. Breathing exercises for chronic obstructive pulmonary disease. Cochrane database Syst Rev.

2012;10(10):CD008250.

84. Vitacca M, Clini E, Bianchi L, Ambrosino N. Acute effects of deep diaphragmatic breathing in COPD patients with chronic respiratory insufficiency. Eur Respir J. 1998;11(2):408-15.

85. Gosselink RA, Wagenaar RC, Rijswijk H, Sargeant AJ, Decramer ML. Diaphragmatic breathing reduces efficiency of breathing in patients with chronic obstructive pulmonary disease. Am J Respir Crit Care Med. 1995;151(4):1136-42.

86. Tiep B, Carter R, Zachariah F, Williams AC, Horak D, Barnett M, et al. Oxygen for 
end-of-life lung cancer care: managing dyspnea and hypoxemia. Expert Rev Respir Med. 2013;7(5):479-90.

87. Pawandenat C. Prophylaxis of pneumonia and breathing facilitating activities in tumor patients: Practical tips for health care personnel. Embase Oncol Res Treat. 2017;40(Suppl 3):279.

88. Roberts SE, Stern M, Schreuder FM, Watson T. The use of pursed lips breathing in stable chronic obstructive pulmonary disease: a systematic review of the evidence. Phys Ther Rev. 2009;14(4):240-6.

89. Spahija J, Marchie M de, Ghezzo H, Grassino A. Factors discriminating spontaneous pursed-lips breathing use in patients with COPD. COPD. 2010;7(4):254-61.

90. Roberts SE, Schreuder FM, Watson T, Stern M. Do COPD patients taught pursed lips breathing (PLB) for dyspnoea management continue to use the technique long-term? A mixed methodological study. Physiotherapy. 2017;103(4):465-70.

91. Bianchi R, Gigliotti F, Romagnoli I, Lanini B, Castellani C, Binazzi B, et al. Patterns of chest wall kinematics during volitional pursed-lip breathing in COPD at rest. Respir Med. 2007;101(7):1412-8.

92. van der Schans CP, de Jong W, Kort E, Wijkstra PJ, Koëter GH, Postma DS, et al. Mouth pressures during pursed lip breathing. Physiother Theory Pract. 1995;11(1):29-34.

93. Spahija J, de Marchie M, Grassino A. Effects of Imposed Pursed-Lips Breathing on Respiratory Mechanics and Dyspnea at Rest and During Exercise in COPD. Chest. 2005;128(2):640-50.

94. Boulding R, Stacey R, Niven R, Fowler SJ. Dysfunctional breathing: A review of the literature and proposal for classification. Eur Respir Rev. 2016;25(141):287-94.

95. Barker NJ, Elphick H, Everard ML. The impact of a dedicated physiotherapist clinic for children with dysfunctional breathing. ERJ Open Res. 2016;2(3):00103-2015.

96. Thomas M, McKinley RK, Freeman E, Foy C, Price D. The prevalence of dysfunctional breathing in adults in the community with and without asthma. Prim Care Respir J. 2005;14(2):78-82.

97. Law N, Ruane LE, Low K, Hamza K, Bardin PG. Dysfunctional breathing is more frequent in chronic obstructive pulmonary disease than in asthma and in health. Respir Physiol Neurobiol. 2018;247:20-3.

98. Gysels $\mathrm{MH}$, Higginson IJ. The lived experience of breathlessness and its implications for care: a qualitative comparison in cancer, COPD, heart failure and MND. BMC Palliat Care. 2011;10(1):15.

99. Barker N, Everard ML. Getting to grips with "dysfunctional breathing." Paediatr Respir Rev. 2015;16(1):53-61. 
100. Courtney R, van Dixhoorn J, Greenwood KM, Anthonissen ELM. Medically unexplained dyspnea: partly moderated by dysfunctional (thoracic dominant) breathing pattern. J Asthma. 2011;48(3):259-65.

101. NHS Choices COPD. 2015. Available from: http://www.nhs.uk/conditions/Chronicobstructive-pulmonary-disease/Pages/Introduction.aspx

102. NHS. Breathlessness - Be Clear on Cancer. Available from: https://www.nhs.uk/beclear-on-cancer/symptoms/out-of-breath\#k7iZ6JQ4PK1OCBxY.97

103. Ramachandra P, Booth S, Pieters T, Vrotsou K, Huppert FA. A brief self-administered psychological intervention to improve well-being in patients with cancer: results from a feasibility study. Psychooncology. 2009;18(12):1323-6.

104. Farquhar MC. Supporting Informal Carers. In: Bausewein C, Currow DC, Johnson MJ, editors. ERS Monograph 73: Palliative Care in Respiratory Disease Chapter 4. 2016.

105. Farquhar M. Carers and breathlessness. Curr Opin Support Palliat Care. 2017;11(3):165-73.

106. Ewing G, Penfold C, Benson JA, Mahadeva R, Howson S, Burkin J, et al. Clinicians' Views of Educational Interventions for Carers of Patients With Breathlessness Due to Advanced Disease: Findings From an Online Survey. J Pain Symptom Manage. 2017;53(2):265-71.

107. Farquhar M, Penfold C, Walter FM, Kuhn I, Benson J. What Are the Key Elements of Educational Interventions for Lay Carers of Patients With Advanced Disease? A Systematic Literature Search and Narrative Review of Structural Components, Processes and Modes of Delivery. J Pain Symptom Manage. 2016;52(1):117130.e27.

108. Farquhar M, Penfold C, Benson J, Lovick R, Mahadeva R, Howson S, et al. Six key topics informal carers of patients with breathlessness in advanced disease want to learn about and why: MRC phase I study to inform an educational intervention. PLoS One. 2017;12(5):e0177081.

109. Farquhar MC, Prevost AT, McCrone P, Brafman-Price B, Bentley A, Higginson IJ, et al. The clinical and cost effectiveness of a Breathlessness Intervention Service for patients with advanced non-malignant disease and their informal carers: mixed findings of a mixed method randomised controlled trial. Trials. 2016;17:185.

110. Johnson M, Kanaan M, Richardson G, Nabb S, Barton R, Torgerson D, et al. A randomised controlled trial of three or one breathing technique training sessions for breathlessness in people with malignant lung disease

BMC Med. 2015; 13; 214.

111. Johnson MJ, Currow DC. Treating breathlessness in lung cancer patients: the potential of breathing training. Expert Rev Respir Med. 2016;10(3):241-3. 
112. Banzett RB. Measuring dyspnoea : new multidimensional instruments to match our 21st century understanding. Eur Respir J. 2017;49:1602473.

113. Shipman C, White S, Gysels M, White P. Access to care in advanced COPD: factors that influence contact with general practice services. Prim Care Respir J. 2009 Dec;18(4):273-8.

114. Booth S, Ryan R, Spathis A. Service delivery of complex interventions for refractory breathlessness. Curr Opin Support Palliat Care. 2016;10(3):228-35.

115. Bausewein C, Schunk M, Schumacher P, Dittmer J, Bolzani A, Booth S. Breathlessness services as a new model of support for patients with respiratory disease. Chron Respir Dis. 2018;15(1):48-59

116. Booth S, Moosavi SH, Higginson IJ. The etiology and management of intractable breathlessness in patients with advanced cancer: a systematic review of pharmacological therapy. Nat Clin Pract Oncol. 2008;5(2):90-100.

117. Johnson MJ, Bland JM, Oxberry SG, Abernethy AP, Currow DC. Opioids for chronic refractory breathlessness: patient predictors of beneficial response. Eur Respir J. 2013 Sep;42(3):758-66.

118. Johnson MJ, Hui D, Currow DC. Opioids, Exertion, and Dyspnea: A Review of the Evidence. Am J Hosp Palliat Med. 2014;33(2):194-200.

119. Rutter M. Resilience as a dynamic concept. Dev Psychopathol. 2012;24:335-44.

120. Stagl JM, Bouchard LC, Lechner SC, Blomberg BB, Gudenkauf LM, Jutagir DR, et al. Long-term psychological benefits of cognitive-behavioral stress management for women with breast cancer: 11-year follow-up of a randomized controlled trial. Cancer. 2015];121(11):1873-81.

121. Mustafa M, Carson-Stevens A, Gillespie D, Edwards AG. Psychological interventions for women with metastatic breast cancer. Cochrane Database Syst Rev. 2013;(6):CD004253.

122. Andersen BL, Yang H-C, Farrar WB, Golden-Kreutz DM, Emery CF, Thornton LM, et al. Psychologic intervention improves survival for breast cancer patients. Cancer. 2008;113(12):3450-8.

123. Vassbakk-Brovold K, Antonsen AJ, Berntsen S, Kersten C, Fegran L. Experiences of Patients With Breast Cancer of Participating in a Lifestyle Intervention Study While Receiving Adjuvant Chemotherapy. Cancer Nurs. 2017 [epub ahead of print] doi:10.1097/NCC.0000000000000476

124. Min J-A, Yoon S, Lee C-U, Chae J-H, Lee C, Song K-Y, et al. Psychological resilience contributes to low emotional distress in cancer patients. Support Care Cancer. 2013;21(9):2469-76.

125. Brown G, Harris T. Social Origins of Depression. London: Tavistock; 1978. 
126. Boelen PA, Reijntjes A, J. Djelantik AAAM, Smid GE. Prolonged grief and depression after unnatural loss: Latent class analyses and cognitive correlates. Psychiatry Res. 2016;240:358-63.

127. Lenferink LIM, Piersma E, De Keijser J, Smid GE, Boelen PA. Cognitive therapy and eye movement desensitization and reprocessing for reducing psychopathology among disaster-bereaved individuals: study protocol for a randomized controlled trial. Eur $\mathrm{J}$ Psychotraumatol. 2017;8(1):1388710.

128. Helmreich I, Kunzler A, Chmitorz A, König J, Binder H, Wessa M, et al. Psychological interventions for resilience enhancement in adults. Cochrane Database Syst Rev. 2017;(2):CD012527.

129. ** Tawakol A, Ishai A, Takx RA, Figueroa AL, Ali A, Kaiser Y, et al. Relation between resting amygdalar activity and cardiovascular events: a longitudinal and cohort study. Lancet. 2017;389(10071):834-45.

130. Benedetti F, Carlino E, Pollo A. How Placebos Change the Patient's Brain. Neuropsychopharmacology. 2011;36(1):339-54.

131. Ardito RB, Rabellino D. Therapeutic Alliance and Outcome of Psychotherapy: Historical Excursus, Measurements, and Prospects for Research. Front Psychol. $2011 ; 2: 270$.

132. Howard C, Dupont S. "The COPD breathlessness manual": a randomised controlled trial to test a cognitive-behavioural manual versus information booklets on health service use, mood and health status, in patients with chronic obstructive pulmonary disease. npj Prim Care Respir Med. 2014;24:14076.

133. Ngai SPC, Jones AYM, Tam WWS. Tai Chi for chronic obstructive pulmonary disease (COPD). Cochrane Database Syst Rev. 2016;(6):CD009953. 


\begin{tabular}{|c|c|}
\hline Causes in patients with cancer & specific management \\
\hline Infection/pneumonia & $\begin{array}{l}\text { Antibiotics and other standard therapies when appropriate, } \\
\text { individual assessment needed }\end{array}$ \\
\hline $\begin{array}{l}\text { Comorbid conditions associated with increased dead space, e.g. } \\
\text { pulmonary vascular disease, COPD }\end{array}$ & $\begin{array}{l}\text { Optimize medical management of pre-existing/ coincident } \\
\text { conditions }\end{array}$ \\
\hline Deconditioning (lack of exercise) & Rehabilitation (see text) and figure 3 \\
\hline Anaemia & Erythropoietin, blood transfusion where appropriate \\
\hline $\begin{array}{l}\text { Cachexia/sarcopenia possibly leading to breathlessness by an } \\
\text { unknown mechanism, possibly related to systemic inflammation. }\end{array}$ & $\begin{array}{l}\text { Prevention of cachexia: activity }+/ \text { - some dietary supplements }+/ \text { - } \\
\text { anabolic treatments }\end{array}$ \\
\hline $\begin{array}{l}\text { Comorbidities associated with respiratory muscle weakness, e.g. } \\
\text { myasthenia gravis }\end{array}$ & Optimum treatment of all comorbid conditions \\
\hline $\begin{array}{l}\text { Respiratory muscle syndromes associated with cancer, e.g. } \\
\text { Lambert-Eaton syndrome }\end{array}$ & Treatment of underlying disease is most effective treatment \\
\hline $\begin{array}{l}\text { COPD associated with lung (and therefore thoracic) } \\
\text { hyperinflation, leading to inefficiency of respiratory muscles }\end{array}$ & Optimum treatment and palliation of COPD \\
\hline Lymphangitis carcinomatosis & $\begin{array}{l}\text { Treatment of cancer, often palliative care, although trial of high- } \\
\text { dose steroids }(60 \mathrm{mg} \text { prednisolone then taper) may be used, most } \\
\text { effective management is treatment of underlying condition but } \\
\text { this is often not possible }\end{array}$ \\
\hline $\begin{array}{l}\text { Tumour obstructing an airway, pleural effusions, pleural disease, } \\
\text { e.g. mesothelioma }\end{array}$ & $\begin{array}{l}\text { Standard oncological/surgical treatment according to patient's } \\
\text { condition, e.g. radiotherapy and/or stenting, etc. }\end{array}$ \\
\hline $\begin{array}{l}\text { Fibrosis following pulmonary emboli, radiotherapy, chemotherapy } \\
\text { (e.g. bleomycin) }\end{array}$ & $\begin{array}{l}\text { Prevention of fibrosis where possible by early standard } \\
\text { intervention in these conditions (e.g. anticoagulation or steroids) } \\
\text { or prevention by surveillance during cancer therapy and careful } \\
\text { control of chemoradiation dosage }\end{array}$ \\
\hline $\begin{array}{l}\text { Conditions affecting the compliance of the chest wall/ diaphragm, } \\
\text { such as hepatomegaly/ascites splinting diaphragm, pleural disease, } \\
\text { e.g. mesothelioma, or chest wall infiltration by tumour }\end{array}$ & Treat as appropriate \\
\hline Comorbid conditions, e.g. asthma, COPD, interstitial lung disease & Ensure optimum treatment of comorbid conditions \\
\hline $\begin{array}{l}\text { Pulmonary congestion, e.g. from SVCO, heart failure, pulmonary } \\
\text { emboli, pericardial effusion }\end{array}$ & $\begin{array}{l}\text { Standard therapy for underlying cancer or treatment of } \\
\text { complication of cancer, prevention optimum (e.g. LMWH) }\end{array}$ \\
\hline $\begin{array}{l}\text { Hypoxia is a consequence of many conditions associated with } \\
\text { cancer including pulmonary emboli, pleural effusions, } \\
\text { lymphangitis carcinomatosis, diaphragmatic splinting (e.g. in } \\
\text { ascites or hepatomegaly), infections }\end{array}$ & $\begin{array}{l}\text { Assess contribution of hypoxia to breathlessness in that individual } \\
\text { and treat underlying conditions as appropriate }\end{array}$ \\
\hline \multicolumn{2}{|c|}{ Abbreviations: COPD, chronic obstructive pulmonary disease; LMWH, low-molecular-weight heparin; SVCO, superior vena cava obstruction. } \\
\hline \multicolumn{2}{|c|}{$\begin{array}{l}\text { Modified after 'The etiology and management of intractable breathlessness in patients with advanced cancer: } \\
\text { a systematic review of pharmacological therapy' Booth S, Moosavi SH, and Higginson IJ (2008) Nature Clinical Practice } \\
\text { Oncology 5;2:90-100 }\end{array}$} \\
\hline See also Dudgeon D and Baracos VE, Current Opinion in Supp & oortive and Palliative Care: (2016) 10: 3, 236-241 \\
\hline
\end{tabular}


Table 2 Summary of available quantitative evidence from trials on interventions for breathlessness in all conditions

\begin{tabular}{|c|c|c|c|}
\hline Intervention & Evidence available & & Comment \\
\hline $\begin{array}{l}\text { Multiprofessional } \\
\text { integrated } \\
\text { breathlessness services }\end{array}$ & $\begin{array}{l}\text { NRS distress due to } \\
\text { breathlessness } \\
(-0 \cdot 24 ;-1 \cdot 30-0 \cdot 82 \text {; one trial, } \\
\mathrm{n}=87)^{18} \\
\text { CRQ mastery (MD } 0 \cdot 58 \text {; } \\
95 \% \text { Cl } 0.01-1 \cdot 15 ; \text { one trial, } \\
\mathrm{n}=105)^{31}\end{array}$ & & $\begin{array}{l}\text { Trial in cancer patients } \\
\text { only (19) } \\
\text { Breathlessness of all } \\
\text { aetiologies (31) }\end{array}$ \\
\hline $\begin{array}{l}\text { Trials of component } \\
\text { interventions }\end{array}$ & $\begin{array}{l}\text { Breathing techniques - } \\
\text { Hand-held fan- VAS } \\
\text { breathlessness severity }\end{array}$ & $\begin{array}{l}6 \text { min walk (MD } \\
45 \text { metres; } 95 \% \\
\text { CI } 29-61 \text { two } \\
\text { trials, } \mathrm{n}=74) ;{ }^{83} \\
\text { Pt reported intensity of } \\
\text { SOB over last } 24 \\
\text { hours on NRS, higher } \\
\text { scores = worse SOB, } \\
6.81 \text { (SD, } 1.89 \text { ) to } \\
5.84(2.39) \text { at week } 4 . \\
\text { No difference between } \\
3 \text { and } 1 \text { session. } \\
\mathrm{P}=0.83, \mathrm{n}=156 \\
\\
\text { (i) }(-7.0 \mathrm{~mm} ;-2.5 \text { to }- \\
11.7 ; \text { one trial, } \\
\mathrm{n}=50) ; 5 \\
\end{array}$ & $\begin{array}{l}\text { Participants had range } \\
\text { of advanced diseases, } \\
\text { majority had COPD } \\
\text { Patients with advanced } \\
\text { cancer } \\
\text { Mixed group mainly } \\
\text { COPD } \\
\text { Lung cancer patients }\end{array}$ \\
\hline
\end{tabular}




\begin{tabular}{|c|c|c|c|}
\hline & $\begin{array}{l}\text { support and education } \\
\text { for family and } \\
\text { caregivers }\end{array}$ & opinion $^{72}$ & \\
\hline $\begin{array}{l}\text { Cognitive behavioural } \\
\text { therapy (CBT) }\end{array}$ & $\begin{array}{l}\text { CRQ dyspnoea (MD } \\
4 \cdot 4 \text {; one trial, } n=222) \text {; } \\
\text { CRQ mastery }(2 \cdot 6 \text {; one } \\
\text { trial, } n=222)^{132}\end{array}$ & & $\begin{array}{l}\text { COPD trial only, other } \\
\text { trials of CBT in cancer } \\
\text { without SOB }\end{array}$ \\
\hline Tai Chi & $\begin{array}{l}\text { CRQ dyspnoea }(0.05 ; \\
95 \% \mathrm{Cl}-1.32-1.42) \\
\text { CRQ mastery }(-0.89 ; \\
0 \cdot 30-1.47 ; \text { two trials, } \\
\mathrm{n}=48)^{133}\end{array}$ & & $\begin{array}{l}\text { COPD only, can be } \\
\text { done sitting }\end{array}$ \\
\hline $\begin{array}{l}\text { CRQ chronic respiratory } \\
\text { questionnaire, }\end{array}$ & $\begin{array}{l}\text { NRS, numerical rating } \\
\text { scale, } \\
\text { Cl confidence interval. }\end{array}$ & & $\begin{array}{l}\text { COPD, chronic } \\
\text { obstructive pulmonary } \\
\text { disease }\end{array}$ \\
\hline
\end{tabular}

$\mathrm{NRS}=$ numerical rating scale, $\mathrm{CRQ}=$ chronic respiratory questionnaire, $\mathrm{VAS}=$ visual analogue scale, COPD = chronic obstructive pulmonary disease, $\mathrm{Cl}=$ confidence interval MD = mean difference MBS modified Borg score , SD standard deviation 
Fig 3 The Spiral of Disability

\section{Spiral of Disability}

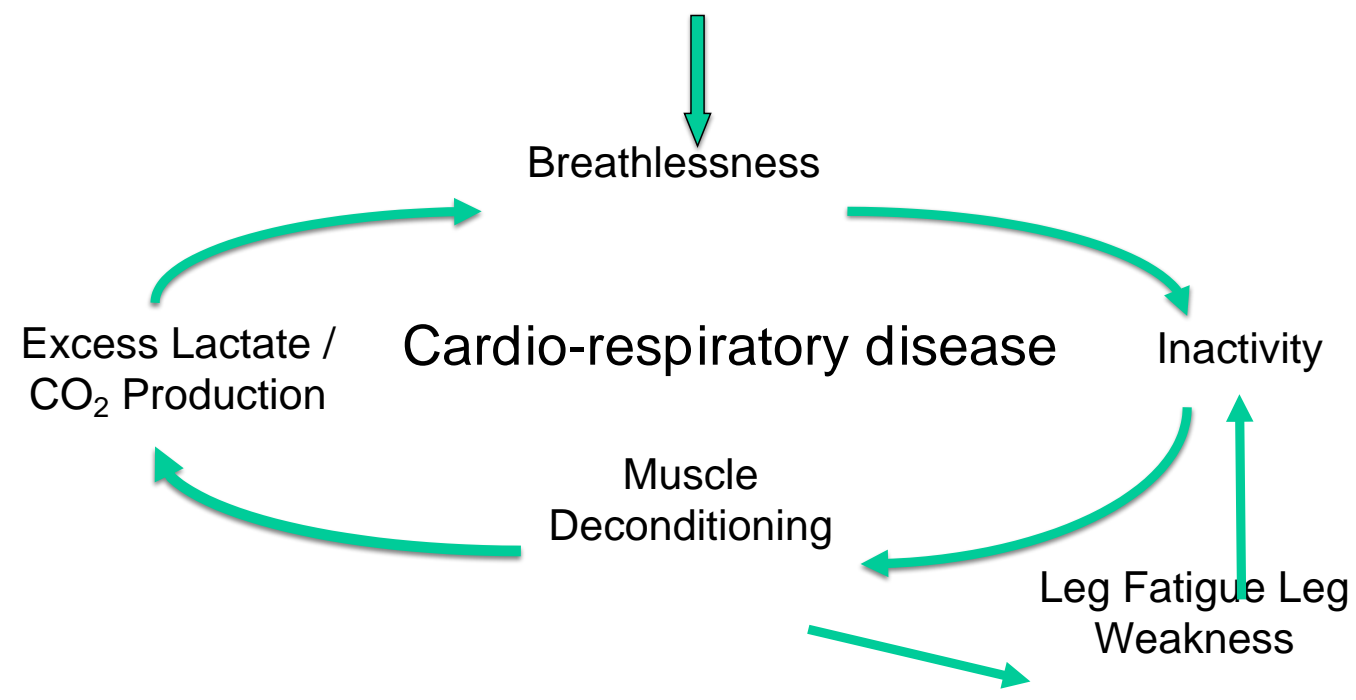


Figure $4^{77}$

Boom and Bust Cycle: reproouced with permlsaston
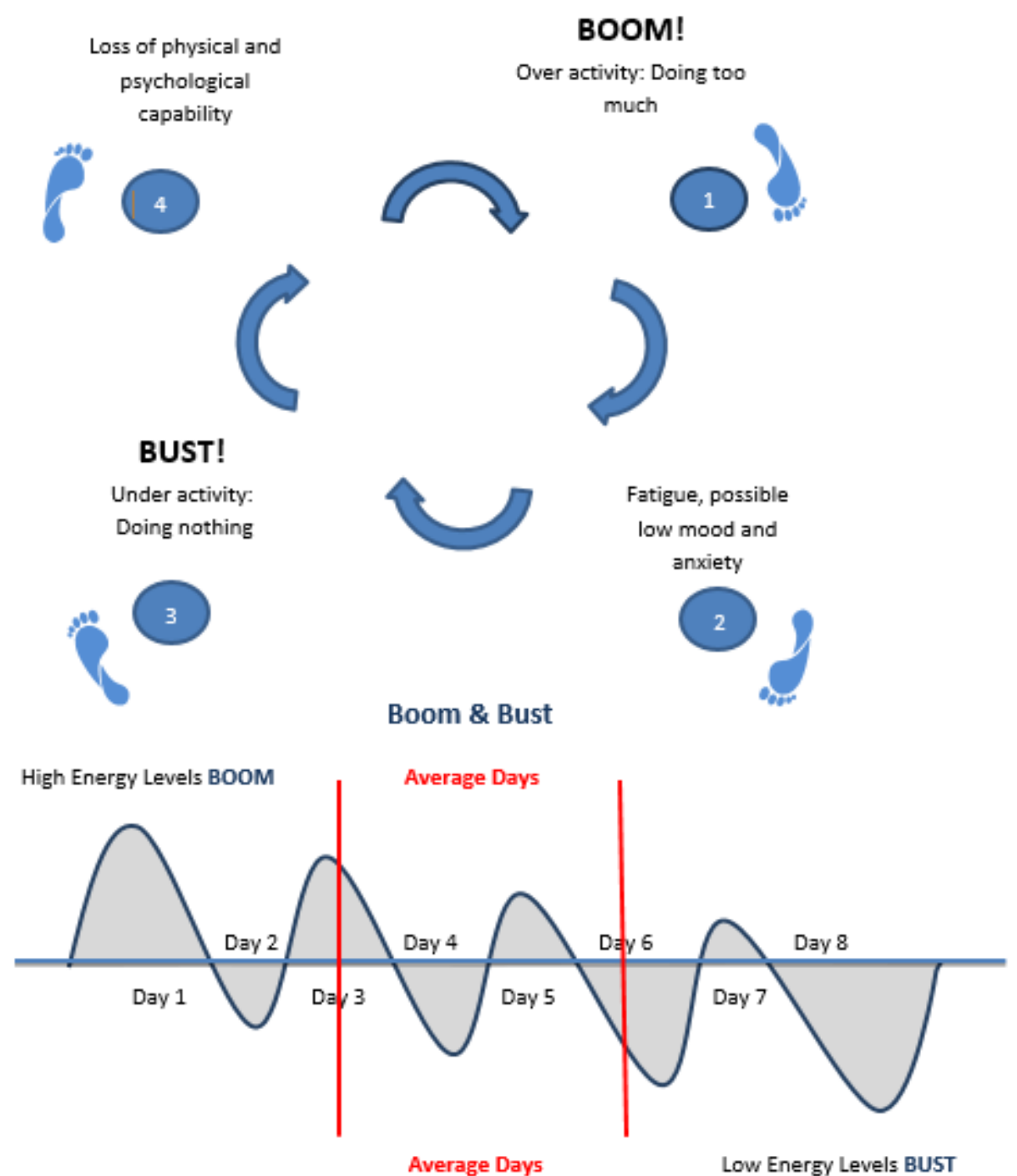